\title{
Resolving the Market Learning-Firm Competitive Advantage Debate, an Empirical Investigation: An Abstract
}

\author{
Jay Weerawardena and Sandeep Salunke
}

\begin{abstract}
While the role of market learning in firm performance outcomes has been at the core of strategic marketing literature for over two decades, this research has been inconclusive. This paper attempts to resolve this by examining how market learning relates to other sources of learning. Adopting the capabilities view of competitive advantage and organizational learning approaches to innovation, we theorize that (a) market learning capability necessitates innovative firms to engage in network learning and internal experimental learning and (b) the three learning capabilities lead to both technical and nontechnical innovation enabling the firm to gain sustained competitive advantage. The findings of the two-stage research design support our theorization that market learning plays a dominant role in the innovationbased competitive advantage process. Our results reveal complex relationships between learning capabilities, innovation types, and components of the sustained competitive advantage construct. Implications to theory and practice and directions for future research are presented.
\end{abstract}

\footnotetext{
J. Weerawardena $(\bowtie)$

UQ Business School, University of Queensland, Brisbane, QLD, Australia

e-mail: j.weerawardena@business.uq.edu.au

\section{S. Salunke}

QUT Business School, Queensland University of Technology, Brisbane, QLD, Australia e-mail: sandeep.salunke@qut.edu.au
} 